\title{
A pedicle screw system and a lamina hook system provide similar primary and long-term stability: a biomechanical in vitro study with quasi-static and dynamic loading conditions
}

\author{
Hans-Joachim Wilke ${ }^{1}$ Dominik Kaiser ${ }^{4}$ - David Volkheimer ${ }^{1}$ - Carsten Hackenbroch $^{2}$ • \\ Klaus Püschel $^{3} \cdot$ Michael Rauschmann $^{4}$
}

Received: 14 July 2015/Revised: 4 May 2016/ Accepted: 21 June 2016/Published online: 12 July 2016

(C) The Author(s) 2016. This article is published with open access at Springerlink.com

\begin{abstract}
Purpose For the stabilization of the thoracolumbar spine area, various stabilization techniques have been developed in recent decades. The aim of these techniques is to immobilize the treated segment to repositioning or correct the spine and guaranty long-term stability to achieve a reliable fusion. The aim of this study was to simulate in an in vitro experiment the postoperative long-term situation in elderly osteoporotic patients to compare two different stabilization principles; a pedicle screw system and a lamina hook system.

Methods Two comparable groups with respect to age and bone mineral density with each $n=6$ fresh-frozen human, bi-segmental thoracolumbar spine specimens (T11-L1) were used. Antero-posterior and lateral radiographs were taken before the test, to assess the spinal status. Then the intact specimens were biomechanically characterized with pure moments in the three anatomical planes in different
\end{abstract}

Hans-Joachim Wilke

hans-joachim.wilke@uni-ulm.de

1 Institute of Orthopaedic Research and Biomechanics, Trauma Research Center Ulm, University of Ulm, Helmholtzstrasse 14, 89081 Ulm, Germany

2 Department of Radiology, German Armed Forces Hospital Ulm, Oberer Eselsberg 40, 89081 Ulm, Germany

3 Department of Legal Medicine, University Medical Center Hamburg-Eppendorf, Butenfeld 34, Hamburg, Germany

4 Orthopädische Universitätsklinik Friedrichsheim gGmbH, Marienburgstraße 2, 60528 Frankfurt am Main, Germany states in terms of range of motion and neutral zone. After implantation of either, a pedicle screw system or a lamina hook system, the primary stability was determined under the same conditions. Subsequently the specimens were cyclically loaded under complex loading, using a custommade set-up in a dynamic materials testing machine with increasing moments from 3 to $66 \mathrm{Nm}$ until 100,000 cycles or until one of the three defined "failure" criteria was reached. (1) A failure of a bony structure. (2) Exceeding of the threefold ROM of the primary stability after implantation in flexion plus extension. (3) Reaching of the ROM based on the intact state before implantation both in flexion plus extension.

Results The results showed that the ROM was strongly reduced after instrumentation similar for both implant systems in all motion planes. The highest stabilization was found in flexion/extension. During cyclic loading with increasing moments, the ROM increased continuously for both systems. The number of load cycles until one of the failure criteria was reached varied only slightly between the two groups. In the pedicle screw group 30,000 (median) loading cycles (range 5000-80,000) with a corresponding moment of $24 \mathrm{Nm}$ (range 9-54) could be reached. In the lamina hook group 32,500 load cycles (range 20,000-45,000) could be achieved with a corresponding moment of $25.5 \mathrm{Nm}$ (range 18-33). There was a slight trend that the pedicle screw system is influenced more by bone mineral density.

Conclusion Both implant systems provide similar primary stability and similar long-term stability. In the pedicle screw group, there was a stronger correlation between bone mineral density and the reached number of load cycles.

Keywords Lamina hooks - Pedicle screws .

Biomechanics $\cdot$ Cyclic loading $\cdot$ In vitro experiments 


\section{Introduction}

In recent decades, various implant systems have been developed to both, stabilize and to correct the thoracolumbar spine. In order to compare the performance of such implant systems they are mostly tested in biomechanical in vitro studies under quasi-static conditions. The success of these stabilization systems, however, depends not only on the primary stability but also ultimately on the long-term stability. This long-term performance predominantly may depend on the condition of the treated vertebral body. With an increasingly aging population, the prevalence of osteoporosis is growing steadily [1,2]. The most common complication with the instrumentation of osteoporotic bone is the loosening of the implants, as well as the fractures in the adjacent segments [3]. Therefore, the aim of these techniques is to guarantee enough stability of the treated segment to achieve a good fusion.

Currently, there are different principles for dorsal stabilization of the spine. This includes pedicle screw and lamina hook systems. Pedicle screw systems are currently the most common technique for the stabilization of the spine, which requires a stable fixation in the bone $[4,5]$. But a poor bone mineral density in osteoporotic patients can result in a screw loosening [6-9]. Lamina hook systems have the advantage that they are connected directly to the lamina, which may have the advantage of a minimized injury risk for neural structures. In addition, a lamina hook system can be implanted without fluoroscopic control and with less blood loss. Due to the possibility of revision of the lamina hooks, pedicle and vertebral body remain intact. First clinical experience show, that the stability of the laminar hooks in the middle of a multisegmental construct is advantageous and never showed loosening or cutting out, but may fail when used in the cranial end of a long construct, once only one pair of infra-laminar hooks is used. Therefore, using LSZ hooks at the end of a construct, at least three segments should be included. The last instrumented vertebra should be two segments above the apex of the kyphosis in the thoracic spine. It may be assumed that a lamina hook system is less likely to loosen in osteoporotic bone and therefore might cause less postoperative complications [10]. On the other hand, one might also speculate that the lamina might be cut or broken over time in weak vertebrae.

Failure due to loosening of fixation systems is usually not tested in in vitro experiments with assembled constructs. Most experiments are done with pull-out test to investigate the fixation strength of single pedicle screws $[4,11-21]$ or other posterior fixation systems [16, 20, 22]. Sometimes screws are also tested with so-called toggling tests where cyclic bending moments are used [23-27].
Liljenquist et al. compared with such axial pull-out test both pedicle and laminar hooks for the use of scoliosis correction. He interpreted his results that pedicle screws might be beneficial, especially for rigid thoracic curves, since they are significantly more resistant than laminar hooks [20]. In contrast to Liljenquist et al. another study by Cordista et al. showed rather the opposite and suggested to consider hooks as supplementary instrumentation in thoracic vertebrae especially in osteoporotic bone [28]. Hasegawa et al. combined both pedicle screws and a laminar hook at the same vertebra and showed in his study with a toggle-test greater fixation strength for the combination compared to the pedicle screw alone [29]. Another study by Murakami et al. also tested a similar combination of screws and infra-laminar hooks (at both the cranial and the caudal ends of the vertebrae) and confirmed again with a pull-out and a stiffness test these superior findings compared to screws alone [27].

However, in reality implants in the vertebral body are not exposed to axial pull-out loads, but also shear and bending stresses. Thus, pull-out test and toggle tests may not represent realistic in vivo loading conditions experienced by the screws. More realistic may be tests with segments that are instrumented with entire assemblies of implants. This is usually done only in a quasi-static test to compare the primary stability where only a few load cycles are applied [30-33]. Biomechanical tests with many cyclic loading cycles with a whole assembly implanted are rare.

The aim of this biomechanical study was to simulate in an in vitro experiment the postoperative long-term situation in middle-aged patients and to compare two posterior stabilization methods; a pedicle screw system and a lamina hook system.

\section{Methods}

\section{Implants}

A pedicle screw system was compared with a lamina hook system (Fig. 1).

The pedicle screw system „OVALTWIST" (SIGNUS Medizintechnik GmbH, Alzenau, Germany) consists of cannulated polyaxial pedicle screws connected with transverse and longitudinal stabilizers. Pedicle screws sizes $5 \times 45 \mathrm{~mm}$ and $6 \times 50 \mathrm{~mm}$ have been used (Fig. 1a).

The lamina hook system "LSZ3" (SIGNUS Medizintechnik GmbH, Alzenau, Germany) was originally developed to correct three-dimensional deformities but may also be used for short fracture instrumentation (Fig. 1b). The lamina hooks are available with of the size 7.5 and $10 \mathrm{~mm}$, the smaller ones were used for the thoracic region and the 
Fig. 1 a The pedicle screw system and $\mathbf{b}$ the lamina hook system, both with transverse and longitudinal stabilizers and implanted in a plastic model
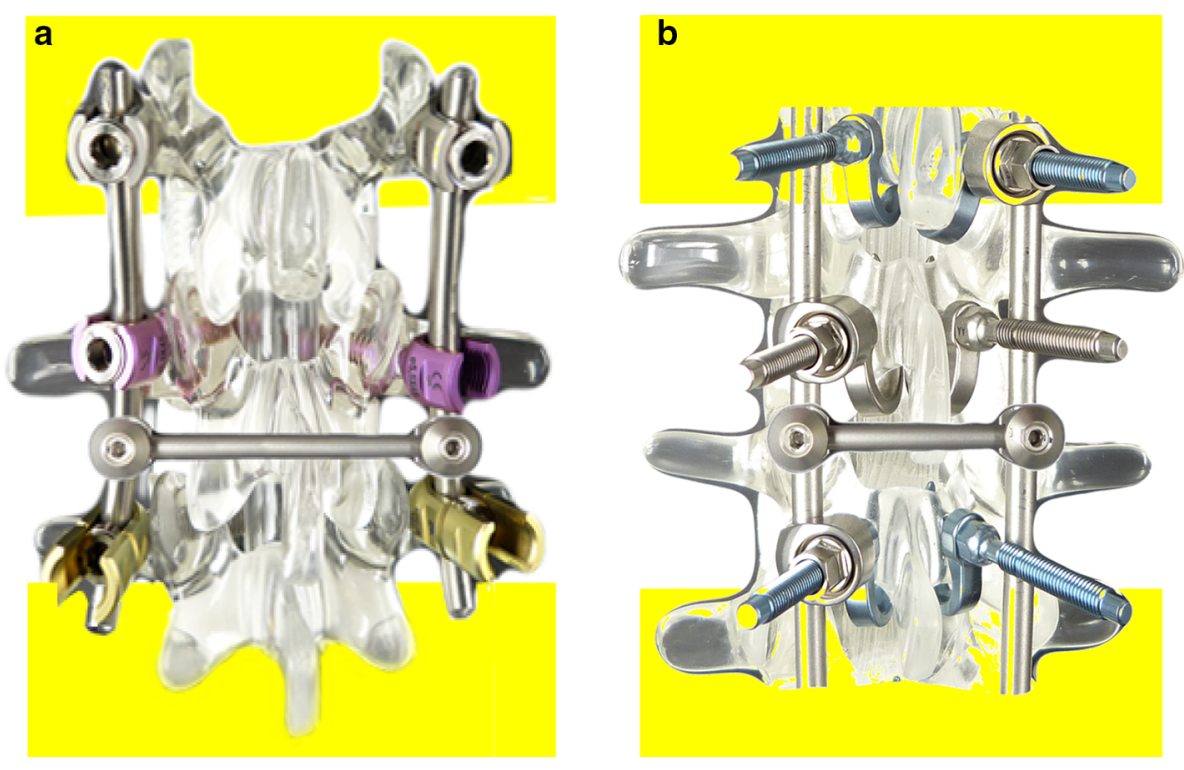
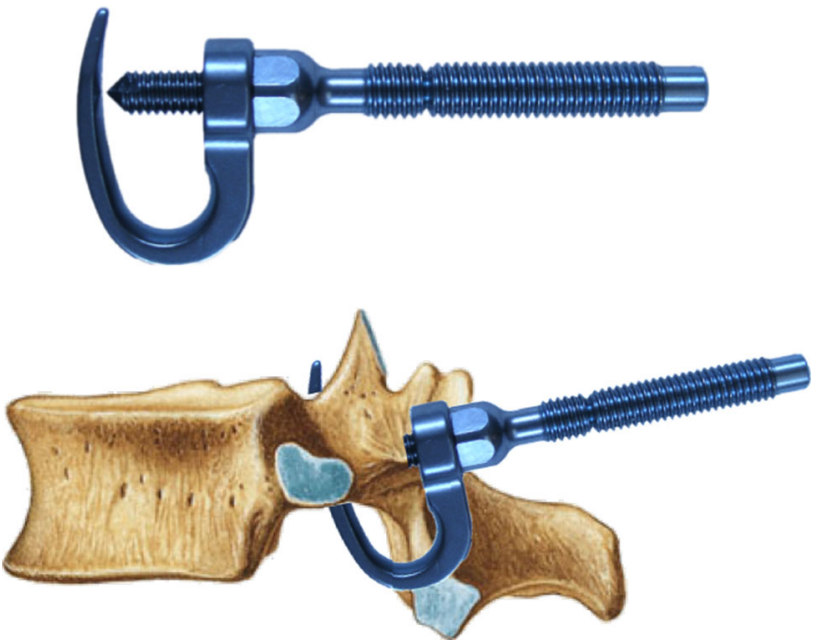

Fig. 2 Infra-lamina hook system

bigger ones for the lumbar region. In this application the rather infra-laminar hook system was connected with transverse connectors and longitudinal stabilizers. These hooks are additionally fixed on the lamina with a perforating screw, to keep the implant in place and increase the initial stability of the system (Fig. 2).

\section{Specimens and preparation}

Twelve fresh frozen human bisegmental thoracolumbar spine specimens (T11-L1) with a median age of 74.5 years (range 47-86 years) were used. The study was approved by the ethical committee board of the University of Ulm (No. 382/12) and all legal and ethical aspects were taken in consideration [34]. The used specimens covered a large range of different bone mineral density values (BMD) from middle aged to elderly people. BMD was determined by computer tomography (Siemens, SOMATOM Definition AS, Erlangen, Germany) as mean value from three consecutive vertebrae L1, L2 and L3. Lateral and posteroanterior $\mathrm{X}$-rays were taken to exclude degenerated and damaged specimens. The specimens were divided into two groups with $n=6$ specimens with comparable age and BMD values (Table 1).

Before preparation, the specimens were thawed overnight at $4{ }^{\circ} \mathrm{C}$ and prepared at room temperature. All soft tissue was removed, leaving the discs, ligaments and joint capsules intact. Then, the upper half of the cranial vertebra and the lower half of the caudal vertebra were embedded in polymethylmethacrylate (PMMA, Technovit 3040, Heraeus Kulzer, Wehrheim, Germany) ensuring the middle disc was aligned horizontally. Flanges were fixed to the cranial and caudal PMMA blocks to mount the specimens in test devices. Care was taken that the posterior part of the specimen with the implant was not affected by the embedding with PMMA. To avoid dehydration all specimens were kept moist with saline solution during the biomechanical tests jetzt Zitatnummer [35].

\section{Test procedure}

First the specimens were characterized in flexibility tests in the intact state and compared with the primary stability after instrumentation. Then they were cyclically loaded up to 100,000 cycles with an increasing load and its effect investigated again in a flexibility test every 5000 cycles.

The flexibility tests were carried out in a spine tester jetzt Zitat [36] with pure moments of $\pm 3.75 \mathrm{Nm}$ in flexion/ extension, lateral bending right/left and axial rotation left/ 
Table 1 Data of the used specimens

\begin{tabular}{lclllll}
\hline Group & Specimen & Gender & Age & BMD [mg Ca-HA/cm $\left.{ }^{3}\right]$ & Reached cycles in flexion + extension & Max. moment [Nm] \\
Pedicle screw group & 1 & $\mathrm{~m}$ & 53 & 105.7 & 80,000 & 54 \\
& 3 & $\mathrm{f}$ & 86 & 65.9 & 30,000 & 24 \\
& 5 & $\mathrm{f}$ & 72 & 46.8 & 5000 & 9 \\
& 7 & $\mathrm{f}$ & 82 & 51.2 & 30,000 & 24 \\
& 9 & $\mathrm{~m}$ & 75 & 77.1 & 40,000 & 30 \\
Median & 11 & $\mathrm{~m}$ & 62 & 97.3 & 30,000 & 24 \\
Lamina hook group & 2 & $\mathrm{~m}$ & 73 & 59.7 & 30,000 & 24 \\
& 4 & $\mathrm{f}$ & 81 & 74.8 & 20,000 & 18 \\
& 6 & $\mathrm{~m}$ & 47 & 112.0 & 45,000 & 33 \\
& 8 & $\mathrm{f}$ & 78 & 105.3 & 35,000 & 27 \\
Median & 10 & $\mathrm{f}$ & 86 & 57.5 & 40,000 & 30 \\
& 12 & $\mathrm{f}$ & 70 & 71.7 & 20,000 & 18 \\
\end{tabular}

Fig. 3 a The spine tester for the flexibility tests with a spinal plastic model and $\mathbf{b}$ a detail of a bisegmental spinal segment equipped with reflecting markers. c The dynamic material testing machine for cyclic loading with a fixed spinal segment
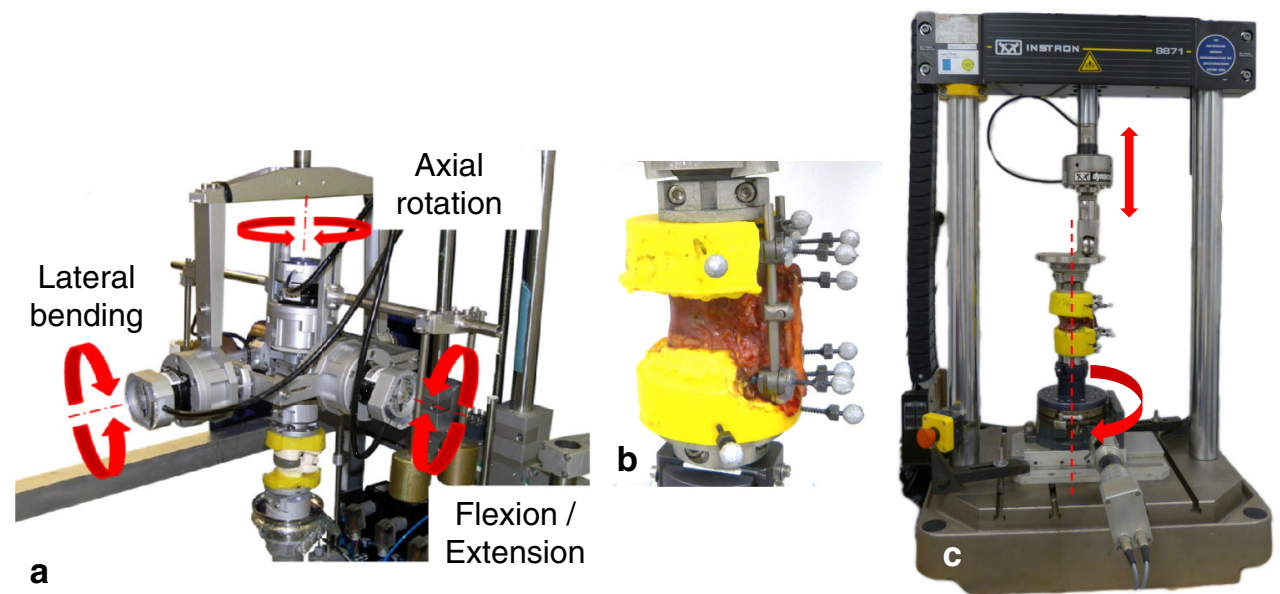

right (Fig. 3a) Zitat [37]. During loading, the specimens were allowed to move unconstrained in the five uncontrolled degrees of freedom. The bending moments and the resulting rotations of the specimens were recorded continuously. Two loading cycles were applied for preconditioning; the third cycle was used for evaluation. The complex, three-dimensional, relative motion of each segment during the flexibility test was recorded using an optical motion analysis system (Vicon MX, Vicon Motion Systems Ltd., Oxford, UK). Three reflecting markers were placed on each vertebra (Fig. 3b) and tracked with the help of six cameras. The system can detect movements in six degrees of freedom and thereby record complex relative movements of polysegmental specimens.

For cyclic loading, the specimens were then taken to a dynamic material testing machine (Instron 8871, Instron Wolpert GmbH, Darmstadt, Germany) where they were flanged to a rotation base, which turned the specimens around its own axis with a speed of $360 \%$ min (Fig. 3c). This base was shifted $30 \mathrm{~mm}(0.03 \mathrm{~m})$ laterally to produce an eccentric sinusoidal loading of the specimens with a frequency of $3 \mathrm{~Hz}$. During the whole dynamic test a preload of $100 \mathrm{~N}$ was applied and during the first 5000 cycles the specimens were loaded with a maximum force of $300 \mathrm{~N}$ and the applied moment alternated between 3 and $9 \mathrm{Nm}$ (Table 2; Fig. 4). The applied force and the resulting moment increased in blocks, respectively, after 5000 load cycles. Furthermore the motion data of the implant in the cranial vertebra ( $\mathrm{T} 11)$ relative to $\mathrm{T} 11$ and the implant in the caudal vertebrae (L1) relative to $\mathrm{L} 1$ were recorded.

Implant loosening has been determined as an indirect value from the increase of the motion of the whole construct by quantifying the increase of the ROM between T11 and L1 after each block of 5000 cycles. 
Table 2 Increase of the defined 5000 cycles) permanent load (in blocks of

\begin{tabular}{ll}
\hline$F_{\mathrm{m}}(n)=150+10 * n$ & Mean force in $\mathrm{N}$ \\
\hline$A_{\mathrm{F}}(n)=50+10 * n$ & Amplitude of mean force in $\mathrm{N}$ \\
$F_{\max }(n)=100$ to $(200+20 * n)$ & Maximum force of dynamic load in $\mathrm{N}$ \\
$M_{\max }(n)=F(n) * r$ & Maximum moment at maximum load in Nm \\
\hline$n=5,10,15, \ldots(5$ corresponds to 5000,10 to 10,000, etc. $\ldots$ load cycles $)$ \\
$r=0.03$ m; length of lever arm
\end{tabular}

Fig. 4 Test procedure with flexibility tests and progression of the dynamic loading tests

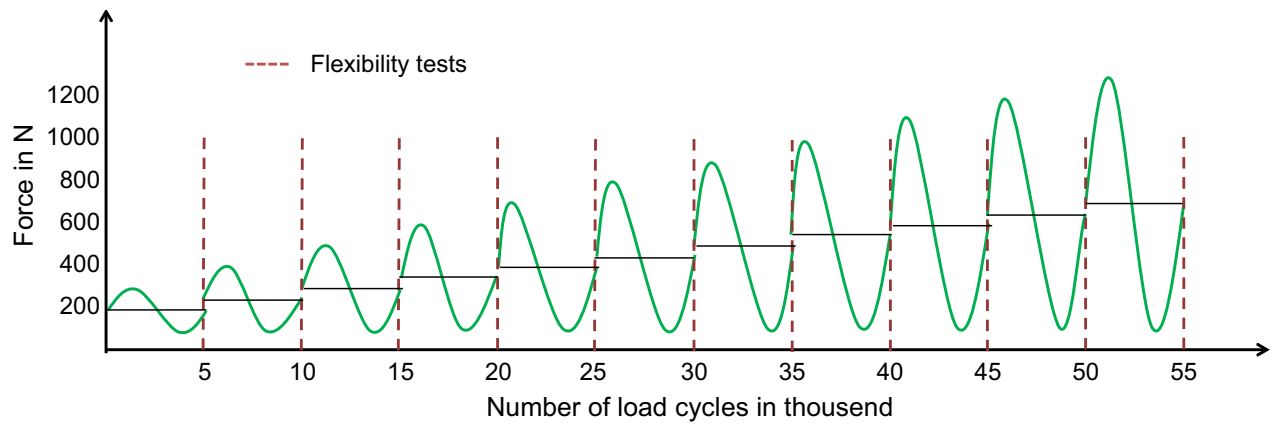

The specimens were kicked out of the evaluation process after one of the following three defined "failure" criteria was reached:

1. Fracture of a bony structure during cyclic loading or loosening in the PMMA embedding.

2. Exceeding of the threefold total ROM, based on the primary stability of the instrumented condition in flexion plus extension.

3. Reaching the original ROM based on the intact state before implantation in flexion plus extension.

\section{Data analysis}

The Mann-Whitney $U$ test ( $p=0.05$ ) was used to determine statistical differences of the ROM between the both independent test groups. The Wilcoxon signed rank test $(p=0.05)$ was used for comparisons within each test group. Since this study was explorative, the $p$ values were not corrected for multiple comparisons. Therefore, they only indicate trends.

The linear relationship between BMD and number of reached load cycles was accomplished by means of a regression analysis.

\section{Results}

The ROM data of the intact bisegmental specimens before instrumentation showed that both specimen groups were comparable with respect to the flexibility in all motion planes $(p \geq 0.63)$. The median values for the pedicle screw group was $7.3^{\circ}$ and $6.6^{\circ}$ for the lamina hook group in flexion + extension (Fig. 5), $5.6^{\circ}$ for both systems in lateral bending (Table 3 ) and $2.8^{\circ}$ for both systems in axial rotation (Table 4). Both implant systems, the pedicle screw and the lamina hook system, lead to a significant stabilization of the treated segments after implantation $(p<0.05)$. The ROM was reduced by 88 and $85 \%$ in flexion + extension, by 67 and $41 \%$ in lateral bending right + left, and by 44 and $21 \%$ in axial rotation left + right, respectively, compared to the intact state without implant (100\%).

The subsequent cyclic loading showed that the risk of loosening was similar between the pedicle screw and the lamina hook systems for flexion/extension (Fig. 5). In lateral bending and axial rotation, the deviation of the ROM in general was larger. Particularly, the lamina hook system showed a tendency to lower rigidity. With an increasing number of load cycles one specimen after the other reached one of the defined "failure" criteria (Table 1). The first specimen from the pedicle screw group dropped out after 5000 cycles at a maximum moment of $9 \mathrm{Nm}$ because it reached the threefold ROM of the instrumented state. In the same specimen a fracture of the lower vertebrae at the interface to the PMMA occurred after 25,000 cycles. The first two specimens from the hook group failed after 20,000 cycles at $18 \mathrm{Nm}$ for the same reason as above. All three first drop-out specimens had very low BMD values. At 40,000 load cycles, meanwhile at a moment of $30 \mathrm{Nm}$, only two specimens in each group were left in the evaluation. Only one specimen with a pedicle screw system reached 80,000 load cycles at a moment of $54 \mathrm{Nm}$. However, one specimen (no. 6) with a hook system showed still a very 
Fig. 5 Total ROM for flexion plus extension

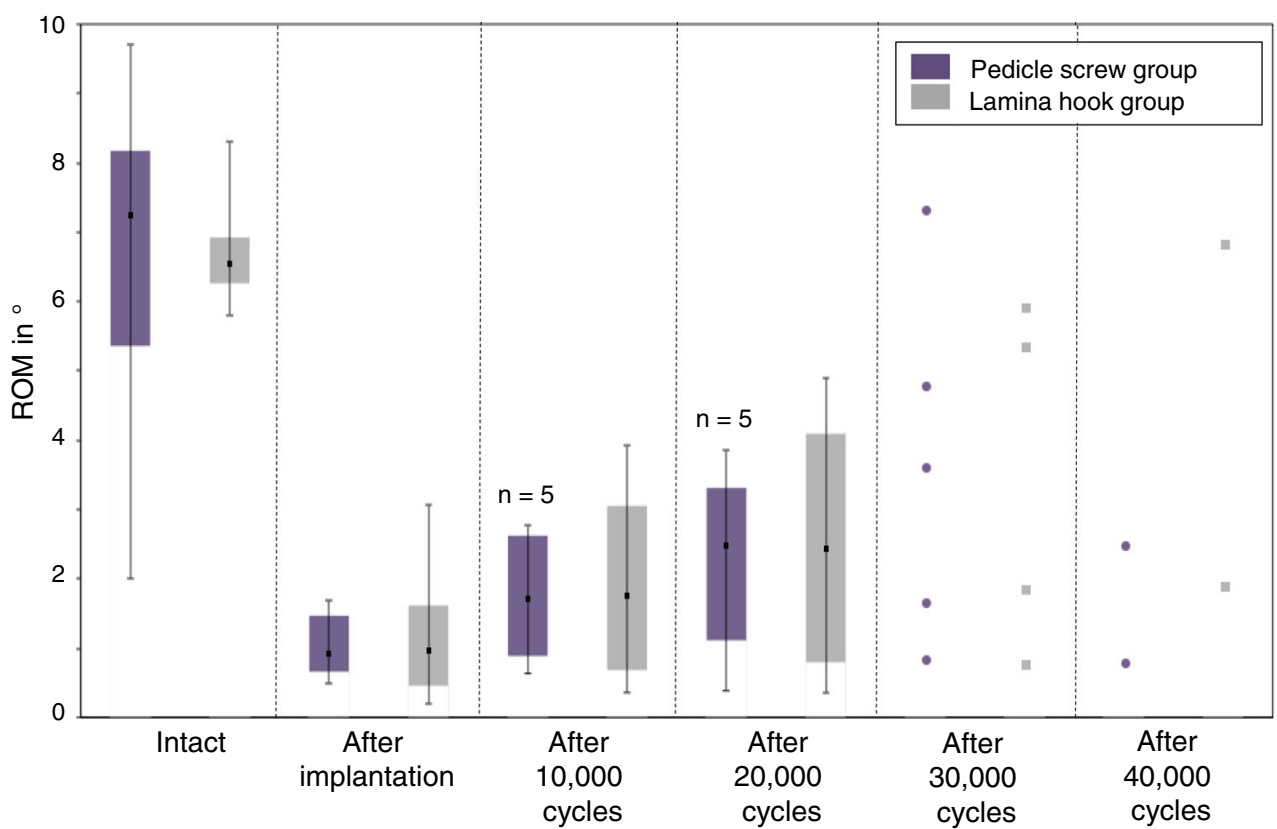

Table 3 Total ROM in lateral bending (right + left) with median values (ranges) in ${ }^{\circ}$

\begin{tabular}{lllllll}
\hline & Intact & $\begin{array}{l}\text { After } \\
\text { implantation }\end{array}$ & $\begin{array}{l}\text { After 10,000 } \\
\text { cycles }\end{array}$ & $\begin{array}{l}\text { After 20,000 } \\
\text { cycles }\end{array}$ & $\begin{array}{l}\text { After 30,000 } \\
\text { cycles }\end{array}$ & $\begin{array}{l}\text { After 40,000 } \\
\text { cycles }\end{array}$ \\
\hline Pedicle screw & $5.5(1.1 / 11.6)$, & $\begin{array}{c}1.8(0.7 / 3.6), \\
n=6\end{array}$ & $\begin{array}{c}2.3(0.7 / 4.2), \\
n=5\end{array}$ & $\begin{array}{c}2.9(0.9 / 4.0), \\
n=5\end{array}$ & $\begin{array}{c}4.1(0.9 / 8.1), \\
n=5\end{array}$ & $\begin{array}{l}1.0, n=1 \\
\text { group }\end{array}$ \\
$\begin{array}{l}\text { Lamina hook } \\
\text { group }\end{array}$ & $\begin{array}{c}5.6(3.6 / 14.3), \\
n=6\end{array}$ & $\begin{array}{c}3.3(1.7 / 5.5), \\
n=6\end{array}$ & $\begin{array}{c}4.8(1.7 / 6.2), \\
n=6\end{array}$ & $\begin{array}{c}5.6(1.7 / 7.7), \\
n=6\end{array}$ & $\begin{array}{c}6.1(0.9 / 8.2), \\
n=4\end{array}$ & $\begin{array}{c}5.6, n=1 \\
9.9, n=1\end{array}$ \\
\hline
\end{tabular}

Table 4 Total ROM in axial rotation (left + right) with median values (ranges) in ${ }^{\circ}$

\begin{tabular}{lllllll}
\hline & Intact & $\begin{array}{l}\text { After } \\
\text { implantation }\end{array}$ & $\begin{array}{l}\text { After 10,000 } \\
\text { cycles }\end{array}$ & $\begin{array}{l}\text { After 20,000 } \\
\text { cycles }\end{array}$ & $\begin{array}{l}\text { After 30,000 } \\
\text { cycles }\end{array}$ & $\begin{array}{l}\text { After 40,000 } \\
\text { cycles }\end{array}$ \\
\hline $\begin{array}{c}\text { Pedicle screw } \\
\text { group }\end{array}$ & $2.7(1.2 / 7.4)$, & $\begin{array}{c}1.5(0.7 / 2.5), \\
n=6\end{array}$ & $\begin{array}{c}1.6(0.9 / 2.2), \\
n=5\end{array}$ & $\begin{array}{c}1.8(0.9 / 2.6), \\
n=5\end{array}$ & $\begin{array}{c}2.3(0.8 / 3.0), \\
n=5\end{array}$ & $\begin{array}{l}0.9, n=1 \\
1.8, n=1\end{array}$ \\
$\begin{array}{l}\text { Lamina hook } \\
\text { group }\end{array}$ & $\begin{array}{c}2.8(1.0 / 12.5), \\
n=6\end{array}$ & $\begin{array}{c}2.2(0.6 / 7.3), \\
n=6\end{array}$ & $\begin{array}{c}2.9(0.5 / 8.0), \\
n=6\end{array}$ & $\begin{array}{c}3.1(0.7 / 8.7), \\
n=6\end{array}$ & $\begin{array}{c}3.6(0.8 / 8.8), \\
n=4\end{array}$ & $\begin{array}{c}2.8, n=1 \\
9.8, n=1\end{array}$ \\
\hline
\end{tabular}

high stiffness after 90,000 cycles, i.e., the ROM was still only $19 \%$ compared to intact state $(100 \%)$. This specimen showed a very high primary stability of $3 \%$ of the intact state but exceed the threefold ROM already after 35,000 load cycles. The motion measurement also suggests that the pedicle screws and the lamina hooks in the lower vertebrae loosen more than in the upper vertebra. However, this should be discussed carefully because the lever arm acting on the lower screws is larger compared to the upper screws due to the tilt of the segment.

A weak correlation between BMD and the reached number of load cycles until "failure" suggests that the performance of pedicle screws may be more dependent on the quality of bone $(r=0.605)$ than the lamina hooks ( $r=0.406$ ) (Fig. 6). Macroscopically, we could not detect that the hooks cut through the lamina as suspected before the tests.

\section{Discussion}

In this biomechanical in vitro study, the primary stability and also the long-term stability after cyclic loading using a set-up for complex dynamic testing was determined and 


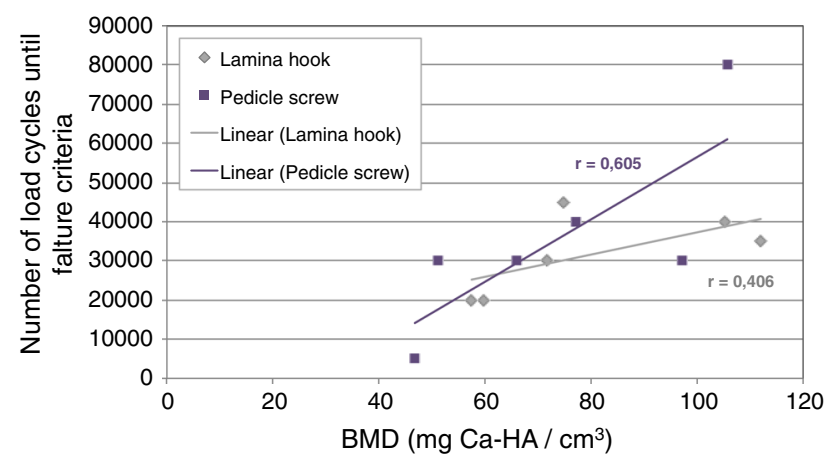

Fig. 6 Correlation of the two test groups between BMD and reached load cycles in flexion plus extension

compared between a pedicle screw system and a lamina hook system. The tests showed similar primary and longterm stability in flexion/extension and a tendency to more flexibility in lateral bending and axial rotation. The differences were not significant for both the primary stability and the risk of loosening between both stabilization systems.

For this test we chose specimens with an age range between 50 and 90 years to be able to cover a large range of bone quality from non-osteoporotic (BMD $>80 \mathrm{mg} / \mathrm{cm}^{3}$ ) to osteoporotic specimens (BMD $<80 \mathrm{mg} / \mathrm{cm}^{3}$ ). This strategy allowed us to find a slight tendency for an increasing screw loosening with decreasing the bone mineral density. This tendency might be slightly lower for the loss of stability with the lamina hook system $(r=0.406)$ compared to the pedicle screw system $(r=0.605)$.

Macroscopic inspection showed that the hooks did not cut through the lamina and did not fracture the lamina what might be expected for spines with a poor bone quality. As described above the hooks are additionally fixed on the lamina with a perforating screw, to keep the implant in place and increase the initial stability of the system. This is a unique feature of this system; other lamina hook systems usually have no additional screw. Therefore, it may not be speculated that these results also apply to competitive systems.

The flexibility tests were performed according internationally accepted guidelines for in vitro testing of spinal implants with pure moments and without preload at room temperature jetzt Zitat [37]. Most of such flexibility tests are typically performed with moment of between 7.5 and $10 \mathrm{Nm}$. In this experiment we decided to reduce this moment to $3.75 \mathrm{Nm}$ because previous experiments have shown that mainly in axial rotation pedicle screws bear the risk to break out form osteoporotic vertebrae if higher moments are applied. Since these specimens were heavily loaded during the cyclic test the flexibility test should be performed on the save side.
The cyclic test was performed using a well-established dynamic test set-up, which has been used in several other experiments, e.g., to compare vertebro- and kyphoplasty methods jetzt [38], to provoke extrusion of nucleus implants jetzt [39], to test annulus sealing implants [40] or to produce an experimental herniation [41]. This is the first time this test set-up was used for bi-segmental fixation system to provoke an implant loosening. To our knowledge, this is also the first test with long-term cyclic loading of whole specimens instrumented with fixation devices. Although, on the first glace it seems to be a suitable method because it allows a combination of compression, shear and bending, which has been described by Rohlmann et al. to be physiological [42-44] there is one limitation.

The application of an eccentric load at the upper vertebra leads to an increased moment in the lower vertebra the stronger the specimen is bent. This may explain why the cranial screws loosened less than the caudal screws. Therefore, the difference for loosening between cranial and caudal screws should be discussed with care and have not been further reported. This may therefore be different in patients [6].

The protocol for the cyclic test was designed to apply a maximum of 100,000 cycles. This number of load cycles can be considered as a good compromise to mimic many load cycles but also to finish the whole test within $12 \mathrm{~h}$ because material properties might change beyond that. In order to have a failure or loosening of the implant system before these 100,000 cycles the loads were increased every 5000 cycles. Other groups have suggested already similar protocols for dynamic testing of single screws with increasing load [45-47].

Three "Failure" criteria for this experiment were defined. They determined whether the test had to be stopped before a maximum of 100,000 load cycles were reached. The most obvious "Failure" criteria was a fracture of a bony structure. The second criterion was to stop the experiment when the ROM of the specimen was exceeding the threefold total ROM in flexion/extension of the postoperative situation, because we assumed this is representing a loosened implant. Nevertheless, this second criteria has to be discussed more in detail. Unfortunately, it turned out that we lost one specimen with hooks (no. 6) too early because the stabilization in this case was so good that a threefold increase still represented a very stiff construct, which could not be considered as loose. Although this specimen still showed only $19 \%$ of the ROM of the intact segment it reached the threefold ROM of the postoperative stability already after 35,000 load cycles. Another specimen (\#1495) was lost already at ca. 25,000 cycles because it became loose in the PMMA embedding. The third criterion was based on the original ROM in flexion/extension of the intact segment. It was assumed that a specimen 
cannot be considered as stabilized anymore when it becomes more flexible than an intact spine.

These failure criteria were defined and concentrated on flexion/extension because this motion plane was considered to be the most important one. This assumption resulted from the experience we had from a series of previous experiments with different implant types (cage subsidence, disc subsidence, nucleus implants extrusion, annulus sealing methods, etc.) using a similar set-up. The criteria were defined before performing the experiment and could not be changed during the evaluation process.

Although we could not find examples where hooks did cut through the lamina, this was found in some clinical cases. This was particularly the case in the most cranial levels when the hooks were used in long constructs, especially when only one segment was fixed with a pair of hooks. Using these infra-laminar hooks in combination with pedicle screws, lead to the fact, that one segment has to be skipped, because the infra-laminar hook can technically not connected in direct neighborhood to the pedicle screw. It may be worthwhile, when using these hooks at the end of a multisegmental construct three segments are included by infra-laminar hooks in order to take care, that the last cranial vertebra is above the kyphosis. Using these type of hooks in the middle of constructs, especially in idiopathic scoliosis patients at the concave side to apply translational forces, a cutting out or loosening was never observed (personal communication by the co-author Rauschmann).

Therefore, it also should be investigated in further studies, maybe using finite element modelling, how many hooks in line are needed, to reduce a clinical cutting out of an infralaminar hook at the cranial end of a long construct. Furthermore a balanced spine in the sagittal profile will most likely reduce a cutting out of infra-laminar hooks, because of reducing stress on the interface of implant and lamina. This study design was considered as compromise because the experimental set-up for the dynamical part allows to test only specimens with a maximum two segments.

Since we speculated that the cutting out happens particularly with poor bone quality, we used in this experiment specimens with a wide range of bone density. Maybe the number of specimens to clearly distinguish this problem was not high enough. On the other hand this failure might only happen if high tensile forces act on the hooks in combination with the set screws and in the case when the sagittal balance is not ideal. In order to further investigate this potential problem additional pull-out test should be performed. Liljenquist et al. described higher pull-out forces for pedicle screws and showed the failure mode of fractures with the lamina hooks [20]. He also showed that there was no significant correlation between BMD and average pull-out strength of the laminar hooks. Our study showed a similar trend, where only a slight correlation with BMD was shown. On the other hand, the lower correlation for the hook might be explained by the different measurement and fixation location although the trabecular BMD was assessed in the vertebral body. But this was done to be as close as possible to the clinic practice.

In real life regeneration and bone remodeling would have improved the stability over the healing time. Since these processes, however, are slower in elderly people we feel that this limitation is acceptable and our test rather simulates a worst-case scenario [38].

\section{Conclusion}

Overall these tests did not show obvious biomechanical disadvantages of the lamina hook system over the tested pedicle screw system and may, therefore, serve as an alternative stabilization method also for the treatment of elderly spines. Further investigations are needed to answer the questions about the clinical use and correct usage in terms of number of infra-laminar hooks and the use at the end of long constructs.

Acknowledgments This study was supported by Signus Medizintechnik GmbH (Alzenau, Germany). We would like thank Rafat Saleh, Martin Braekau, and Simone Schädler for technical support.

\section{Compliance with ethical standards}

Conflict of interest None.

Open Access This article is distributed under the terms of the Creative Commons Attribution 4.0 International License (http://creative commons.org/licenses/by/4.0/), which permits unrestricted use, distribution, and reproduction in any medium, provided you give appropriate credit to the original author(s) and the source, provide a link to the Creative Commons license, and indicate if changes were made.

\section{References}

1. Hadji P, Klein S, Gothe H, Haussler B, Kless T, Schmidt T, Steinle T, Verheyen F, Linder R (2013) The epidemiology of osteoporosis-Bone Evaluation Study (BEST): an analysis of routine health insurance data. Dtsch Arzteblatt Int 110(4):52-57

2. Reginster JY, Burlet N (2006) Osteoporosis: a still increasing prevalence. Bone 38(2 Suppl 1):S4-S9

3. Delank KS, Rollinghoff M, Eysel-Gosepath K, Sobottke R, Eysel P (2010) Degeneration and osteoporosis of the spine. Is there a modified procedure? Der Orthopade 39(4):425-431

4. Zdeblick T, Kunz D, Cooke M, McCabe R (1993) Pedicle screw pullout strength correlation with insertional torque. Spine 18(12):1673-1676

5. Boos N, Webb JK (1997) Pedicle screw fixation in spinal disorders: a European view. Eur Spine J 6(1):2-18

6. Galbusera F, Volkheimer D, Reitmaier S, Berger-Roscher N, Kienle A, Wilke HJ (2015) Pedicle screw loosening: a clinically relevant complication? Eur Spine J 24(5):1005-1016 
7. Okuyama K, Abe E, Suzuki T, Tamura Y, Chiba M, Sato K (2001) Influence of bone mineral density on pedicle screw fixation: a study of pedicle screw fixation augmenting posterior lumbar interbody fusion in elderly patients. Spine J 1(6):402-407

8. Wu ZX, Gong FT, Liu L, Ma ZS, Zhang Y, Zhao X, Yang M, Lei W, Sang HX (2012) A comparative study on screw loosening in osteoporotic lumbar spine fusion between expandable and conventional pedicle screws. Arch Orthop Trauma Surg 132(4): 471-476

9. Ponnusamy KE, Iyer S, Gupta G, Khanna AJ (2011) Instrumentation of the osteoporotic spine: biomechanical and clinical considerations. Spine J 11(1):54-63

10. Coe JD, Warden KE, Herzig MA, McAfee PC (1990) Influence of bone mineral density on the fixation of thoracolumbar implants. A comparative study of transpedicular screws, laminar hooks, and spinous process wires. Spine 15(9):902-907

11. Becker S, Chavanne A, Spitaler R, Kropik K, Aigner N, Ogon M, Redl H (2008) Assessment of different screw augmentation techniques and screw designs in osteoporotic spines. Eur Spine J 17(11):1462-1469

12. Burval DJ, McLain RF, Milks R, Inceoglu S (2007) Primary pedicle screw augmentation in osteoporotic lumbar vertebrae: biomechanical analysis of pedicle fixation strength. Spine (Phila Pa 1976) 32(10):1077-1083

13. Chen YL, Chen WC, Chou CW, Chen JW, Chang CM, Lai YS, Cheng CK, Wang ST (2014) Biomechanical study of expandable pedicle screw fixation in severe osteoporotic bone comparing with conventional and cement-augmented pedicle screws. Med Eng Phys 36(11):1416-1420

14. Halvorson TLKL, Thomas KA, Whitecloud TS 3rd, Cook SD (1994) Effect of bone mieneral density on pedicle screw fixation. Spine 19(21):2415-2420

15. Hasegawa T, Inufusa A, Imai Y, Mikawa Y, Lim TH, An HS (2005) Hydroxyapatite-coating of pedicle screws improves resistance against pull-out force in the osteoporotic canine lumbar spine model: a pilot study. Spine J 5(3):239-243

16. Paxinos O, Tsitsopoulos PP, Zindrick MR, Voronov LI, Lorenz MA, Havey RM, Patwardhan AG (2010) Evaluation of pullout strength and failure mechanism of posterior instrumentation in normal and osteopenic thoracic vertebrae. J Neurosurg Spine 13(4):469-476

17. Zindrick M, Wiltse L, Widell E, Thomas JC, Holland WR, Field BT, Spencer CW (1986) A biomechanical study of intrapeduncular screw fixation in the lumbosacral spine. Clin Orthop Relat Res (203):99-112

18. Krenn MH, Piotrowski WP, Penzkofer R, Augat P (2008) Influence of thread design on pedicle screw fixation. Laboratory investigation. J Neurosurg Spine 9(1):90-95

19. Pfeiffer FM, Abernathie DL, Smith DE (2006) A comparison of pullout strength for pedicle screws of different designs: a study using tapped and untapped pilot holes. Spine (Phila Pa 1976) 31(23):E867-E870

20. Liljenqvist U, Hackenberg L, Link T, Halm H (2001) Pullout strength of pedicle screws versus pedicle and laminar hooks in the thoracic spine. Acta Orthop Belg 67(2):157-163

21. Soshi S, Shiba R, Kondo H, Murota K (1991) An experimental study on transpedicular screw fixation in relation to osteoporosis of the lumbar spine. Spine (Phila Pa 1976) 16(11):1335-1341

22. Balabaud L, Gallard E, Skalli W, Dupas B, Roger R, Lavaste F, Steib JP (2003) Biomechanical evaluation of a bipedicular spinal fixation device: three different strength tests. Eur Spine J 12(5):480-486

23. Zhu Q, Kingwell S, Li Z, Pan H, Lu WW, Oxland TR (2012) Enhancing pedicle screw fixation in the aging spine with a novel bioactive bone cement: an in vitro biomechanical study. Spine (Phila Pa 1976) 37(17):E1030-E1037
24. Kueny RA, Kolb JP, Lehmann W, Puschel K, Morlock MM, Huber G (2014) Influence of the screw augmentation technique and a diameter increase on pedicle screw fixation in the osteoporotic spine: pullout versus fatigue testing. Eur Spine $\mathrm{J}$ 23(10):2196-2202

25. Wittenberg RH, Lee KS, Shea M, White AA, Hayes WC (1993) Effect of screw diameter, insertion technique, and bone cement augmentation of pedicular screw fixation strength. Clin Orthop Relat Res 296:278-287

26. Tan JS, Kwon BK, Dvorak MF, Fisher CG, Oxland TR (2004) Pedicle screw motion in the osteoporotic spine after augmentation with laminar hooks, sublaminar wires, or calcium phosphate cement: a comparative analysis. Spine (Phila $\mathrm{Pa}$ 1976) 29(16): $1723-1730$

27. Murakami H, Tsai KJ, Attallah-Wasif ES, Yamazaki K, Shimamura T, Hutton WC (2006) A biomechanical assessment of infralaminar hooks as an alternative to supra-laminar hooks in thoracolumbar fixation. Spine (Phila Pa 1976) 31(9):967-971

28. Cordista A, Conrad B, Horodyski M, Walters S, Rechtine G (2006) Biomechanical evaluation of pedicle screws versus pedicle and laminar hooks in the thoracic spine. Spine J 6(4):444-449

29. Hasegawa K, Takahashi HE, Uchiyama S, Hirano T, Hara T, Washio T, Sugiura T, Youkaichiya M, Ikeda M (1997) An experimental study of a combination method using a pedicle screw and laminar hook for the osteoporotic spine. Spine (Phila Pa 1976) 22(9):958-962 (discussion 963)

30. Melnyk AD, Chak JD, Singh V, Kelly A, Cripton PA, Fisher CG, Dvorak MF, Oxland TR (2015) Characterization of the behavior of a novel low-stiffness posterior spinal implant under anterior shear loading on a degenerative spinal model. Eur Spine $\mathrm{J}$ 24(4):775-782

31. Deviren V, Acaroglu E, Lee J, Fujita M, Hu S, Lenke LG, Polly D Jr, Kuklo TR, O’Brien M, Brumfield D, Puttlitz CM (2005) Pedicle screw fixation of the thoracic spine: an in vitro biomechanical study on different configurations. Spine (Phila Pa 1976) 30(22):2530-2537

32. Schmoelz W, Huber JF, Nydegger T, Dipl I, Claes L, Wilke HJ (2003) Dynamic stabilization of the lumbar spine and its effects on adjacent segments: an in vitro experiment. J Spinal Disord Tech 16(4):418-423

33. Wilke HJ, Kemmerich V, Claes LE, Arand M (2001) Combined anteroposterior spinal fixation provides superior stabilisation to a single anterior or posterior procedure. J Bone Joint Surg $\mathrm{Br}$ 83(4):609-617

34. Puschel K (2016) Teaching and research on corpses. Mortui vivos docent. Rechtsmedizin 26(2):115-118

35. Wilke H-J, Jungkunz B, Wenger K, Claes LE (1998) Spinal segment range of motion as a function of in vitro test conditions: effects of exposure period, accumulated cycles, angulardeformation rate, and moisture condition. Anat Record 251(1):15-19

36. Wilke H-J, Claes L, Schmitt H, Wolf S (1994) A universal spine tester for in vitro experiments with muscle force simulation. Eur Spine J 3(2):91-97

37. Wilke HJ, Wenger K, Claes L (1998) Testing criteria for spinal implants: recommendations for the standardization of in vitro stability testing of spinal implants. Eur Spine J 7(2):148-154

38. Wilke HJ, Mehnert U, Claes LE, Bierschneider MM, Jaksche H, Boszczyk BM (2006) Biomechanical evaluation of vertebroplasty and kyphoplasty with polymethyl methacrylate or calcium phosphate cement under cyclic loading. Spine (Phila Pa 1976) 31(25):2934-2941

39. Kettler A, Kaps HP, Haegele B, Wilke HJ (2007) Biomechanical behavior of a new nucleus prosthesis made of knitted titanium filaments. SAS J 1(4):125-130 
40. Heuer F, Ulrich S, Claes L, Wilke HJ (2008) Biomechanical evaluation of conventional anulus fibrosus closure methods required for nucleus replacement. Laboratory investigation. J Neurosurg Spine 9(3):307-313

41. Wilke HJ, Ressel L, Heuer F, Graf N, Rath S (2013) Can prevention of a reherniation be investigated? Establishment of a herniation model and experiments with an anular closure device. Spine (Phila Pa 1976) 38(10):E587-E593

42. Rohlmann A, Bergmann G, Graichen F (1997) Loads on an internal spinal fixation device during walking. J Biomech 30(1):41-47

43. Rohlmann A, Bergmann G, Graichen F (1999) Loads on internal spinal fixators measured in different body positions. Eur Spine J 8(5):354-359

44. Rohlmann A, Graichen F, Weber U, Bergmann G (2000) 2000 Volvo Award winner in biomechanical studies: Monitoring in vivo implant loads with a telemeterized internal spinal fixation device. Spine (Phila Pa 1976) 25(23):2981-2986

45. Bostelmann R, Keiler A, Steiger HJ, Scholz A, Cornelius JF, Schmoelz W (2015) Effect of augmentation techniques on the failure of pedicle screws under cranio-caudal cyclic loading. Eur Spine J. doi:10.1007/s00586-015-3904-3

46. Goel VK, Winterbottom JM, Weinstein JN (1994) A method for the fatigue testing of pedicle screw fixation devices. J Biomech 27(11):1383-1388

47. Unger S, Erhart S, Kralinger F, Blauth M, Schmoelz W (2012) The effect of in situ augmentation on implant anchorage in proximal humeral head fractures. Injury 43(10):1759-1763 